\title{
Retraction Note: Simulation of plain rainfall runoff and monitoring of basketball players' sports fatigue based on heterogeneous computing
}

\author{
Li Fenglei $^{1,2} \cdot$ Zhang Shengnian $^{1} \cdot$ Cheng Wanxiang $^{1}$
}

Published online: 22 November 2021

(c) Saudi Society for Geosciences 2021

Retraction Note: Arabian Journal of Geosciences (2021) 14: 1527

https://doi.org/10.1007/s12517-021-07901-x

The Editor-in-Chief and the Publisher have retracted this article because the content of this article is nonsensical. The peer review process was not carried out in accordance with the Publisher's peer review policy. Authors Zhang Shengnian and Cheng Wanxiang have not responded to correspondence regarding this retraction. The Publisher has not been able to obtain a current email address for author Li Fenglei.

The original article can be found online at https://doi.org/10.1007/ s12517-021-07901-x.

Zhang Shengnian

zhytt112@163.com

1 School of Physical Education and Sport Training, Shanghai University of Sport, Shanghai 200438, China

2 School of Physical Education, East China University of Technology, Nanchang 330013, Jiangxi, China 